\title{
Early treatment of functional tricuspid regurgitation at the time of mitral valve surgery: an increased risk or an additional benefit?
}

\author{
Paolo Nardi, Calogera Pisano, Antonio Pellegrino, Fabio Bertoldo, Sabrina Ferrante, Monica Greci, \\ Sara Rita Vacirca, Marco Russo, Giovanni Ruvolo \\ Department of Cardiac Surgery, Tor Vergata University Policlinic, Rome 00133, Italy.
}

Correspondence to: Dr. Paolo Nardi, Department of Cardiac Surgery, Tor Vergata University Policlinic, Viale Oxford 81, Rome 00133, Italy. E-mail: pa.nardi4@libero.it

\begin{abstract}
How to cite this article: Nardi P, Pisano C, Pellegrino A, Bertoldo F, Ferrante S, Greci M, Vacirca SR, Russo M, Ruvolo G. Early treatment of functional tricuspid regurgitation at the time of mitral valve surgery: an increased risk or an additional benefit? Vessel Plus 2018;2:4. http://dx.doi.org/10.20517/2574-1209.2017.35
\end{abstract}

Received: 9 Nov 2017 First Decision: 9 Feb 2018 Revised: 24 Feb 2018 Accepted: 7 Mar 2018 Published: 13 Mar 2018

Science Editor: Alexander D. Verin Copy Editor: Jun-Yao Li Production Editor: Cai-Hong Wang

\section{INTRODUCTION}

Functional tricuspid regurgitation (FTR) refers to tricuspid insufficiency occurring secondarily to leftsided heart valve disease, especially mitral stenosis or regurgitation, in the absence of organic lesions of the tricuspid valve. In the late 1960s, the observation that mitral valve surgery sometimes led to an improvement in FTR suggested a conservative approach ${ }^{[1]}$. On the contrary, in the 1970s, Carpentier et al. ${ }^{[2]}$ reported excellent results with tricuspid valve repair, arguing for systematic repair of FTR.

With the increasing population of long-term survivors of prosthetic mitral valve replacement, it has been observed that many patients developed late heart failure as the result of onset or progression of FTR in a severe form. Severe FTR is associated with substantially poorer functional outcomes and survival if untreated $^{[3,4]}$. Moreover, data showing late development of severe FTR in patients with mild or mild-tomoderate regurgitation at the time of mitral valve surgery have more recently pushed towards early aggressive intervention on the tricuspid valve in concomitance with the treatment of mitral valve disease. This raised the question if FTR in the presence of a lesser degree of regurgitation should be treated during the first operation, supporting Carpentier's assertion that "surgical abstention" may be somewhat a dangerous policy. Moreover, when patients require reoperation for tricuspid valve dysfunction, a high operative mortality has been observed, mainly due to the irreversible right ventricular systolic or liver dysfunction ${ }^{[5-7]}$. Increasing data now support an early surgical treatment of $\mathrm{FTR}^{[8-11]}$.

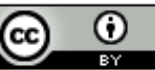

(C) The Author(s) 2018. Open Access This article is licensed under a Creative Commons Attribution 4.0 International License (https://creativecommons.org/licenses/by/4.0/), which permits unrestricted use, sharing, adaptation, distribution and reproduction in any medium or format, for any purpose, even commercially, as long as you give appropriate credit to the original author(s) and the source, provide a link to the Creative Commons license, and indicate if changes were made. 
We have reviewed the current guidelines and several reports for recommending tricuspid valve repair, also in the light of our recent experience in the treatment of FTR. It is our opinion that a dysfunction of the tricuspid valve even if in the early stages of manifestation, should be corrected at the time of concomitant left-sided heart surgery, i.e., mitral valve surgery.

\section{AMERICAN AND EUROPEAN GUIDELINES}

The 2014 American Heart Association/American College of Cardiology guidelines indicate that surgery for the treatment of FTR is required for patients affected by a severe degree of regurgitation (stages C and D of the tricuspid valve disease) undergoing left-sided valve surgery ${ }^{[12]}$. This type of indication is in Class I, with Level C of evidence. Risks and benefits of tricuspid valve surgery should be carefully evaluated in the presence of severe right ventricle systolic dysfunction or irreversible pulmonary hypertension, potentially causing a right ventricle failure after operation. In Class IIa with Level B of evidence, it is recommended the repair of FTR in the presence of mild or moderate tricuspid regurgitation (stage B of the tricuspid valve disease) at the time of left-sided valve surgery either in the presence of tricuspid annular dilation or with prior evidence of right heart failure. In Class IIb with Level C of evidence tricuspid valve repair may be recommended in the presence of moderate FTR (stage B) and pulmonary artery hypertension at the time of left-sided valve surgery. The 2017 European Society of Cardiology/European Association for Cardio-Thoracic Surgery guidelines focus on the timing of surgical intervention based on the concept that surgery of the tricuspid valve should be carried out sufficiently early to avoid late irreversible right ventricular dysfunction or progression of $\mathrm{FTR}^{[13]}$.

In presence of FTR, adding tricuspid valve repair, if indicated during left-sided surgery, not only does not increase the operative risk, but also has been demonstrated to provide reverse remodeling of the right ventricle and to improve the functional status. The indication with Level C of evidence in Class I, IIa, IIb are similar to those reported by the American guidelines, with the exception of Class IIb, where it is stated that surgery may be considered in patients with mild or moderate FTR, even in the absence of annular dilatation, when previous right heart failure has been documented. In both American and European Guidelines the annulus dilatation of the tricuspid valve defined as greater than $40 \mathrm{~mm}$ or $21 \mathrm{~mm} / \mathrm{m}^{2}$ by $2 \mathrm{D}$ echocardiography represents a surgical indication for the treatment. In fact, a diastolic diameter greater than $40 \mathrm{~mm}$ or $21 \mathrm{~mm} / \mathrm{m}^{2}$ increases the risk of persistent or progressive FTR after isolated mitral valve surgery.

\section{TRICUSPID VALVE REPAIR TECHNIQUES}

Repair techniques for the treatment of FTR have been introduced by Kay et al. ${ }^{[14]}$ in 1965 and De Vega ${ }^{[15]}$ in 1972. Kay's technique provides the obliteration of the posterior tricuspid leaflet by placement of several sutures across the posterior segment of the tricuspid valve annulus making the valve as bicuspid. De Vega's technique provides the annuloplasty by placement of two semicircular sutures around the annulus anchored with two pledgets (2-0 Ti-cron), starting from the anterior-septal commissure and ending in front of the origin of the coronary sinus.

Ring annuloplasty, first introduced by Carpentier et al. ${ }^{[2]}$ in 1974 , is thought to offer the best long-term outcomes for severe FTR, by means of a more complete annular stabilization. However, this procedure leads to prolongation of the operation and cardiopulmonary bypass time. Therefore intervening on moderate functional TR in the context of another cardiac procedure may become a decision-making dilemma.

\section{CURRENT EARLY AND LATE RESULTS OF THE REPAIR TECHNIQUES}

Marquis-Gravel et al. ${ }^{[16]}$ examined the outcomes of 926 cases of tricuspid valve surgery performed over a 30year period. Of them, 792 patients underwent tricuspid valve repair ( $85 \%)$ more frequently in concomitance 
with mitral valve surgery (85\%). Tricuspid valve repair was done by the use of De Vega or ring annuloplasty. Operative mortality was $14 \%$, 15-year survival $34 \%$. Risk factors for late mortality included the preoperative severity $>3+$ of the FTR, whereas tricuspid valve surgery concomitantly performed with mitral and/or aortic surgery was not a predictive factor for increased mortality ${ }^{[16]}$. Chan et al ${ }^{[17]}$ studied 624 mitral valve replacement patients. They performed in 125 out of 231 patients having preoperatively a FTR $>2+$ tricuspid repair using De Vega or ring annuloplasty techniques. During a mean follow-up of 6.8 years among patients who had preoperative FTR $>2+$, the regurgitation worsened in $10(8 \%)$ patients who received repair compared with 85 (17\%) who did not. Moreover, the progression of FTR was less developed in the repair group $(P=0.008)^{[17]}$. Navia et al ${ }^{[18]}$ have compared the effectiveness of several tricuspid valve repair techniques in 2277 patients who had undergone left-sided valve surgery. At 10 years of follow-up, the use of a rigid prosthetic ring provided the most sustained reduction of FTR $^{[18]}$.

On the other hand, Yilmaz et al. ${ }^{[19]}$ in a series of 699 patients undergoing mitral valve repair, showed that at 3 years of follow-up, a clinically silent non-severe FTR was unlikely to progress. Huang et al. ${ }^{[20]}$ in a series of 448 patients undergoing tricuspid annuloplasty with concomitant procedures, evaluated the results of the De Vega (216 patients) or ring (232 patients) annuloplasty. The indication to FTR treatment was done on the symptomatic tricuspid regurgitation grade $(4+)(91.3 \%)$ or in presence of moderate FTR $(<4+)$ or marked tricuspid annular dilatation (diameter $>4.0 \mathrm{~cm})(8.7 \%)$. With both types of tricuspid valve repair techniques postoperative echocardiography showed significant improvement of the FTR grade (from 3.4 preoperatively to $0.6, P<0.05)$; 5-year freedom from reoperation ( $81 \% v$ s. $75 \%, P=0.124)$ was similar. They concluded that the De Vega annuloplasty is an acceptable strategy, improving both clinical and echocardiographic status of the patients during long-term follow-up, although the event-free survival appeared to be lower in comparison with that observed for the ring annuloplasty $(74.5 \% v s .78 .8 \%, P=\mathrm{NS})^{[20]}$.

Finally, Takano et al. ${ }^{[21]}$ in a smaller series of 71 patients undergoing mitral valve replacement and tricuspid valve repair, but with a follow-up period of 20 years, identified the preoperative moderate grade of FTR as a significant risk factor for the development of late severe tricuspid regurgitation. They claimed that an aggressive early treatment of FTR at the time of mitral valve surgery may prevent the late progression of the FTR.

In our recent experience, from January 2015 to October 2017, on a series of 156 patients treated for left-sided heart valve disease (mitral, mitral and aortic valve disease), 57 patients (36.5\%) underwent suture annuloplasty techniques (De Vega, 49 patients; Kay, 8 patients). In the mitral surgery group of patients ( $n=114$ ), FTR was treated in 35 cases (30.7\%). Indication for the surgical treatment was given in the presence of symptomatic severe or moderate FTR, or when the diameter of the tricuspid valve annulus reached $40 \mathrm{~mm}$, regardless of symptoms ${ }^{[2,23]}$. We have adopted those tricuspid valve repair techniques because they require less surgical time in comparison with the use of a ring implant. The increased incidence of the surgical treatment of FTR observed in our series is in accordance with that reported in the database of the Society of Thoracic Surgeons. The trend of the tricuspid valve surgery increased with the time: 11,405 patients treated in the first period of analysis (2000-2003), 21,804 and 21,166 in the last periods (2004-2007 and 2008-2010). In this report operative mortality declined from $10.6 \%$ in 2000 to $8.2 \%$ in $2010(P<0.001)^{[24]}$.

In our series the operative mortality for mitral valve repair (29 patients) and mitral plus tricuspid valve repair ( 9 patients) was similar ( $0 \%$ vs. $0 \%$ ), as well as that observed for mitral valve replacement (50 patients) and mitral valve replacement plus tricuspid valve repair (26 patients) ( $2 \%$ vs. $3.6 \%, P=\mathrm{NS})$.

As compared to preoperative period, clinical status of patients surgically treated for FTR during the shortterm follow-up showed a significant improvement in NYHA class $(3.0 \pm 0.7$ preoperatively $v$ s. $1.4 \pm 0.6$ at follow-up), pulmonary artery pressure mean value $(60 \pm 22 v s .32 \pm 10 \mathrm{mmHg})$, mean value of FTR ( $2.8 \pm$ $1.0 / 4+v$ s. $0.7 \pm 0.6 / 4+)(P<0.001$, for all comparisons). None of the patients required permanent pacemaker 
Table 1. Early and late results of the FTR surgical repair

\begin{tabular}{|c|c|c|c|c|}
\hline Authors & Repair techniques & $\begin{array}{l}\text { Operative } \\
\text { mortality }\end{array}$ & Late survival & $\begin{array}{l}\text { Freeedom from recurrence of } \\
\text { significant FTR }\end{array}$ \\
\hline Marquis-Gravel et al. ${ }^{[16]}$ & De Vega, ring implant & $14 \%$ & $55 \%$ at 10 years & $46 \%$ at 10 years \\
\hline Chan et al..$^{[17]}$ & De Vega, ring implant & $3 \%$ & $80 \%$ at 10 years & $75 \%$ at 10 years \\
\hline Navia et al. ${ }^{[18]}$ & De Vega, Kay, ring implant & & $44 \%$ at 10 years & $98 \%$ at 5 years \\
\hline Huang et $a l_{.}^{[20]}$ & De Vega, ring implant & $1.1 \%$ & $\begin{array}{l}84 \%, 97 \% \text { (De Vega vs. ring) at } \\
5 \text { years }\end{array}$ & $\begin{array}{l}75 \%, 79 \% \text { (De Vega vs. ring) at } \\
5 \text { years }\end{array}$ \\
\hline Takano et al. ${ }^{[21]}$ & Ring implant & 0 & $59 \%$ at 15 years & $93 \%$ at 15 years \\
\hline Filsoufi et $\left.a\right|^{[25]}$ & Ring implant & $5.3 \%$ & $85 \%$ at 2 years & $100 \%$ at 2 years \\
\hline Fukuda et al. ${ }^{[26]}$ & Ring implant & 0 & $100 \%$ at 1 year & 70 at 1 year \\
\hline Ghanta et al..27] & Kay, ring implant & $6.4 \%$ & $\begin{array}{l}75 \%, 61 \% \text { (Kay vs. ring) at } \\
3 \text { years }\end{array}$ & $\begin{array}{l}75 \%, 69 \% \text { (Kay vs. ring) at } \\
3 \text { years }\end{array}$ \\
\hline Chang et al. ${ }^{[28]}$ & De Vega, Kay & $3.4 \%$ & $96 \%$ at 8 years & $72 \%$ at 8 years \\
\hline Tang et $a / .^{[29]}$ & De Vega, ring implant & $\begin{array}{l}7 \%, 4 \% \text { (De Vega } \\
\text { vs. ring) }\end{array}$ & $\begin{array}{l}36 \%, 49 \% \text { (De Vega vs. ring) at } \\
15 \text { years }\end{array}$ & $\begin{array}{l}39 \%, 83 \% \text { (De Vega } v s \text {. ring) at } \\
15 \text { years }\end{array}$ \\
\hline McCarthy et $a I^{[30]}$ & De Vega, ring implant & $8 \%$ & $50 \%$ at 8 years & $\begin{array}{l}67 \%, 83 \% \text { (De Vega } v s \text {. ring) at } \\
8 \text { years }\end{array}$ \\
\hline $\begin{array}{l}\text { Our recent experience, } \\
2015-2017\end{array}$ & De Vega, Kay & 0 & $100 \%$ at 1 year & $100 \%$ at 1 year \\
\hline
\end{tabular}

FTR: functional tricuspid regurgitation

implantation at discharge, or during follow-up. Early and late results of surgical treatment of FTR are summarized in Table 1, reporting either data above mentioned than other surgical series.

\section{CONCLUSIONS}

Current data suggest that tricuspid valve repair together with early elective surgical intervention for mitral valve disease should be done in order to improve late outcomes and avoid the risk of a late redo operation due to progression of FTR. In the presence of severe FTR, surgery continues to be recommended in Class I. Annular dilatation and history of congestive heart failure symptoms are important to take the decision to early repair of FTR, although more recent guidelines continue to indicate surgical intervention in these specific subgroup of patients in Class II. We agree that a dysfunction of the tricuspid valve, even if not associated with a severe insufficiency, should be corrected at the time of a surgical operation on the mitral valve, especially if the technique used to repair the tricuspid valve requires a short time of execution.

\section{DECLARATIONS}

\section{Authors' contributions}

Study design: Nardi P

Development of methodology: Nardi P

Collection of data: Ferrante S, Greci M, Vacirca SR, Russo M

Analysis and/or interpretation of data: Pisano C, Pellegrino A, Bertoldo F

Writing of the manuscript: Nardi P

Supervision: Ruvolo G

\section{Financial support and sponsorship}

None.

\section{Conflicts of interest}

There are no conflicts of interest.

\section{Patient consent}

Not applicable. 


\section{Ethics approval}

Not applicable.

\section{Copyright}

(c) The Author(s) 2018.

\section{REFERENCES}

1. Braunwald NS, Ross J Jr, Morrow AG. Conservative management of tricuspid regurgitation in patients undergoing mitral valve replacement. Circulation 1967;35:I63-9.

2. Carpentier A, Deloche A, Hanania G, Forman J, Sellier P, Piwnica A, Dubost C, McGoon DC. Surgical management of acquired tricuspid valve disease. J Thorac Cardiovasc Surg 1974;67:53-65.

3. King RM, Shaff HV, Danielson GK, Gersh BJ, Orszulak TA, Piehler JM, Puga FJ, Pluth JR. Surgery for tricuspid regurgitation late after mitral valve replacement. Circulation 1984;70:I193-7.

4. Cohen SR, Sell JE, McIntosh CL, Clark RE. Tricuspid regurgitation in patients with acquired, chronic, pure mitral regurgitation. I. Prevalence, diagnosis, and comparison of preoperative clinical and hemodynamic features in patients with and without tricuspid regurgitation. J Thorac Cardiovasc Surg 1987;94:481-7.

5. Mangoni AA, DiSalvo TG, Vlahakes GJ, Polanczyk CA, Fifer MA. Outcome following isolated tricuspid valve replacement. Eur J Cardiothorac Surg 2001;19:68-73.

6. Kwon DA, Park JS, Chang HJ, Kim YJ, Sohn DW, Kim KB, Ahn H, Oh BH, Park YB, Choi YS. Prediction of outcome in patients undergoing surgery for severe tricuspid regurgitation following mitral valve surgery and role of tricuspid annular systolic velocity. $A m J$ Cardiol 2006;98:659-61.

7. Kim YJ, Kwon DA, Kim HK, Park JS, Hahn S, Kim KH, Kim KB, Sohn DW, Ahn H, Oh BH, Park YB. Determinants of surgical outcome in patients with isolated tricuspid regurgitation. Circulation 2009;120:1672-8.

8. Benedetto U, Melina G, Angeloni E, Refice S, Roscitano A, Comito C, Sinatra R. Prophylactic tricuspid annuloplasty in patients with dilated tricuspid annulus undergoing mitral valve surgery. J Thorac Cardiovasc Surg 2012;143:632-8.

9. Calafiore AM, Gallina S, Iacò AL, Contini M, Bivona A, Gagliardi M, Bosco P, Di Mauro M. Mitral valve surgery for functional mitral regurgitation: should moderate-or-more tricuspid regurgitation be treated? A propensity score analysis. Ann Thorac Surg 2009;87:698703.

10. Van de Veire NR, Braun J, Delgado V, Versteegh MI, Dion RA, Klautz RJ, Bax JJ. Tricuspid annuloplasty prevents right ventricular dilatation and progression of tricuspid regurgitation in patients with tricuspid annular dilatation undergoing mitral valve repair. $J$ Thorac Cardiovasc Surg 2011;141:1431-9.

11. Chikwe J, Itagaki S, Anyanwu A, Adams DH. Impact of concomitant tricuspid annuloplasty on tricuspid regurgitation, right ventricular function, and pulmonary artery hypertension after repair of mitral valve prolapse. J Am Coll Cardiol 2015;65:1931-8.

12. Nishimura RA, Otto CM, Bonow RO, Carabello BA, Erwin JP 3rd, Guyton RA, O’Gara PT, Ruiz CE, Skubas NJ, Sorajja P, Sundt TM 3rd, Thomas JD; American College of Cardiology/American Heart Association Task Force on Practice Guidelines. AHA/ACC guideline for the management of patients with valvular heart disease: a report of the American College of Cardiology/American Heart Association Task Force on Practice Guidelines. J Am Coll Cardiol 2014;63:57-185.

13. Baumgartner H, Falk V, Bax JJ, De Bonis M, Hamm C, Holm PJ, Iung B, Lancellotti P, Lansac E, Muñoz DR, Rosenhek R, Sjögren J, Tornos Mas P, Vahanian A, Walther T, Wendler O, Windecker S, Zamorano JL; ESC Scientific Document Group. 2017 ESC/EACTS Guidelines for the management of valvular heart disease. Eur Heart $J$ 2017;38:2739-91.

14. Kay JH, Maselli-Campagna G, Tsuji HK. Surgical treatment of tricuspid insufficiency. Ann Surg 1965;162:53-8.

15. De Vega NF. La anuloplastiaselectiva, regulable y permanente. Rev Esp Cardiol 1972;25:555-6.

16. Marquis-Gravel G, Bouchard D, Perrault LP, Pagé P, Jeanmart H, Demers P, Carrier M, Cartier R, Poirier NC, Hébert Y, Pellerin M. Retrospective cohort analysis of 926 tricuspid valve surgeries: clinical and hemodynamic outcomes with propensity score analysis. $\mathrm{Am}$ Heart $J$ 2012;163:851-8.

17. Chan V, Burwash IG, Lam BK, Auyeung T, Tran A, Mesana TG, Ruel M. Clinical and echocardiographic impact of functional tricuspid regurgitation repair at the time of mitral valve replacement. Ann Thorac Surg 2009;88:1209-15.

18. Navia JL, Nowicki ER, Blackstone EH, Brozzi NA, Nento DE, Atik FA, Rajeswaran J, Gillinov AM, Svensson LG, Lytle BW. Surgical management of secondary tricuspid valve regurgitation: annulus, commissure, or leaflet procedure? J Thorac Cardiovasc Surg 2010;139:1473-82.

19. Yilmaz O, Suri RM, Dearani JA, Sundt TM 3rd, Daly RC, Burkhart HM, Li Z, Enriquez-Sarano M, Schaff HV. Functional tricuspid regurgitation at the time of mitral valve repair for degenerative leaflet prolapse: the case for a selective approach. $J$ Thorac Cardiovasc Surg 2011;142:608-13.

20. Huang X, Gu C, Men X, Zhang J, You B, Zhang H, Wei H, Li J. Repair of functional tricuspid regurgitation: comparison between suture annuloplasty and rings annuloplasty. Ann Thorac Surg 2014;97:1286-92.

21. Takano H, Hiramatsu M, Kida H, Uenoyama M, Horiguchi K, Yamauchi T, Kin K, Shirakawa Y, Kaneko M, Daimon T. Severe tricuspid regurgitation after mitral valve surgery: the risk factors and results of the aggressive application of prophylactic tricuspid valve repair. Surg Today 2017;47:445-56. 
22. Dreyfus GD, Corbi PJ, Chan KM, Bahrami T. Secondary tricuspid regurgitation or dilatation: which should be the criteria for surgical repair? Ann Thorac Surg 2005;79:127-32.

23. Anyanwu AC, Chikwe J, Adams DH. Tricuspid valve repair for treatment and prevention of secondary tricuspid regurgitation in patients undergoing mitral valve surgery. Curr Cardiol Rep 2008;10:110-7.

24. Kilic A, Saha-Chaudhuri P, Rankin JS, Conte JV. Trends and outcomes of tricuspid valve surgery in North America: an analysis of more than 50,000 patients from the Society of Thoracic Surgeons database. Ann Thorac Surg 2013;96:1546-52; discussion 1552.

25. Filsoufi F, Salzberg SP, Coutu M, Adams DH. A three-dimensional ring annuloplasty for the treatment of tricuspid regurgitation. Ann Thorac Surg 2006;81:2273-7.

26. Fukuda S, Gillinov AM, McCarthy PM, Stewart WJ, Song JM, Kihara T, Daimon M, Shin MS, Thomas JD, Shiota T. Determinants of recurrent or residual functional tricuspid regurgitation after tricuspid annuloplasty. Circulation 2006;114:I582-7.

27. Ghanta RK, Chen R, Narayanasamy N, McGurk S, Lipsitz S, Chen FY, Cohn LH. Suture bicuspidization of the tricuspid valve versus ring annuloplasty for repair of functional tricuspid regurgitation: midterm results of 237 consecutive patients. J Thorac Cardiovasc Surg 2007;133:117-26.

28. Chang BC, Song SW, Lee S, Yoo KJ, Kang MS, Chung N. Eight-year outcomes of tricuspid annuloplasty using autologous pericardial strip for functional tricuspid regurgitation. Ann Thorac Surg 2008;86:1485-92; discussion 1493.

29. Tang GH, David TE, Singh SK, Maganti MD, Armstrong S, Borger MA. Tricuspid valve repair with an annuloplasty ring results in improved long-term outcomes. Circulation 2006;114:I577-81.

30. McCarthy PM, Bhudia SK, Rajeswaran J, Hoercher KJ, Lytle BW, Cosgrove DM, Blackstone EH. Tricuspid valve repair: durability and risk factors for failure. J Thorac Cardiovasc Surg 2004;127:674-85. 